\title{
Concepção de educação do MST: uma análise a partir da ANPED
}

Clarice Carolina Ortiz de Camargo1; Leonice Matilde Richter2; Rafael Martins Mendes; Sirlei Aparecida Martins Ferreira ${ }^{4}$

\section{Resumo}

O presente texto analisa a produção acadêmica da Associação Nacional de Pós Graduação e Pesquisa em Educação (ANPED) em relação à concepção de educação presente no Movimento dos Trabalhadores Rurais Sem Terra (MST). Desenvolveu-se uma pesquisa documental, na qual foram avaliados materiais do sítio do Movimento, o Dossiê MST Escola e a pesquisa de cinco Grupos de Trabalho (GT) da ANPED de 2000-2010, envolvendo uma análise de 923 trabalhos, dos quais 17 foram selecionados, com base nos resumos dos artigos que tratavam da temática educação no MST. A concepção de educação popular do movimento sustenta-se no referencial freireano e na diferença de classes como fator de exclusão dos sujeitos das classes populares. Os artigos desvelaram o processo dialético na relação intrínseca entre a concepção de mundo, homem e educação. Os princípios filosóficos e pedagógicos estiveram presentes naqueles que consideraram a educação como um terreno de lutas para a transformação social. Identificamos, ainda, propostas pautadas no humanismo e no socialismo, em que estão valorizados o coletivo, a partilha e a justiça social. Todas as publicações, por fim, apontaram para conceitos-chave das relações estabelecidas, como a dialogicidade, a participação ativa dos estudantes, a construção coletiva, a gestão compartilhada, o processo de formação ético-política e a reflexão-ação crítica para a transformação social.

\section{Palavras-chave}

Educação Popular. MST. ANPED.

1. Mestre em Educação pela Universidade Federal de Uberlândia, professora da alfabetização inicial na Escola de Educação Básica na Universidade Federal de Uberlândia. E-mail: claricecarolinacamargo@gmail.com.

2. Doutoranda em Educação na Universidade Federal de Uberlândia, docente da Faculdade de Ciências Integradas do Pontal da Universidade Federal de Uberlândia, membro do Grupo de Estudos e Pesquisa em Avaliação (GEPAE) e do Grupo de Estudos e Pesquisas em Políticas, Educação e Cidadania (Pólis). E-mail: rleonice@pontal.ufu.br.

3. Mestre em Ensino de Química pela Universidade Federal de Uberlândia, professor da rede estadual de ensino de Uberlândia. E-mail: rafaelsamm@yahoo.com.br.

4. Especialista em Filosofia pela Universidade Federal de Uberlândia, pedagoga, coordenadora na Pró-reitoria de Extensão, Cultura e Assuntos Estudantis da Universidade Federal de Uberlândia. E-mail: sirleiproex@yahoo.com. br. 


\title{
The concept of education in Brazil's Landless Workers Movement: an analysis based on ANPED
}

Clarice Carolina Ortiz de Camargo*; Leonice Matilde Richter ${ }^{* *}$; Rafael Martins Mendes ${ }^{* * *}$; Sirlei Aparecida Martins Ferreira****

\begin{abstract}
This text analysis the academic production of the National Association of Graduate Studies and Research in Education (Associação Nacional de Pós-Graduação e Pesquisa em Educação - ANPED) regarding the concept of education in the Brazil's Landless Workers Movement (Movimento dos Trabalhadores Rurais Sem Terra - MST). It was developed a documental research through the evaluation of articles in the MST's webpage and in the dossier of the MST's school. It was also analysed 923 articles in five Thematic Sessions of the ANPED (2000-2010); out of the total, it was chosen 17 articles whose subject was the education in the MST. The concept of popular education in the movement is based on Freire's referential and in the social class difference as a factor of exclusion of people in low-class. The articles revealed a dialectic process in the intrinsic relation between the concepts of world, humanity and education. Philosophical and pedagogical principles were present in those articles that considered education the basis of struggles for social transformations. It was also identified proposes based on humanism and socialism, valuing collective actions, equal sharing and social justice. Finally, every article pointed out key-concepts of the established relations, such as the dialogicity, students' active participation, collective construction, shared management, the ethical and political formation process and the critical reflection and action for a social transformation.
\end{abstract}

\section{Keywords}

Popular Education. MST. ANPED.

\footnotetext{
* Master in Education from the Federal University of Uberlândia, teacher of initial literacy at Escola de Educação Básica of the Federal University of Uberlândia. E-mail: claricecarolina@gmail.com.

** Doctoral student at the Federal University of Uberlândia, professor at Integrated Science Faculty of Pontal at the Federal University of Uberlândia, member of Evaluation Studies and Researches Group (GEPAE) and of Politics, Education and Citizenship Studies and Researches Group (Pólis). E-mail: rleonice@pontal.ufu.br.

*** Master in Chemistry Teaching from the Federal University of Uberlândia, teacher in the state education system of Uberlândia. E-mail: rafaelsamm@yahoo.com.br.

*** Specialist in Philosophy from the Federal University of Uberlândia, pedagogue, coordinator in the ProRectorate of Extension, Culture and Student Affairs of the Federal University of Uberlândia. E-mail: sirleiproex@ yahoo.com.br.
} 


\section{Introdução}

O Movimento dos Trabalhadores Rurais Sem Terra (MST) representa, desde sua constituição, em 1984, em Cascavel-PR, de acordo com Silva (2009b), uma ação de homens e mulheres que, indignados com a estrutura social vigente, se mobilizaram contra a sociedade capitalista e a cultura individualista/ meritocrática que a sustenta. Em torno da luta pela terra, o Movimento aponta para a constituição de princípios coletivos e decisões partilhadas. Nessa conjuntura, a educação assume o propósito de uma formação para a problematização e a transformação das relações sociais constituídas historicamente no campo.

O MST, compreendendo o significado da educação como elemento fundamental de sustentação da luta dos trabalhadores rurais, constituiu um setor ${ }^{5}$ para tratar da educação, no qual tomou como base o referencial freireano. Freire (1996) assumia uma concepção de educação problematizadora, alicerçada na própria materialidade vivida pelos educandos, visto que, para ele, a educação deveria garantir a leitura e a intervenção consciente do homem no mundo. Segundo Pavan (2011, p. 257) os interesses de Freire "sempre foram os da educação popular".

Permeados por essas delimitações, neste texto temos como propósito tecer reflexões acerca da produção acadêmica publicada entre 2000 e 2010, no âmbito da Associação Nacional de Pós-Graduação e Pesquisa em Educação (ANPED) em relação à concepção de educação presente no MST. Neste sentido, nossa problemática envolve a identificação das aproximações e diferenciações da concepção de educação apregoada nos artigos da ANPED com a pedagogia do Movimento. Para tanto, desenvolvemos uma pesquisa bibliográfica abarcando as produções dos Grupos de Trabalho - Movimentos Sociais e Educação (GT 3); Educação Popular (GT 6); Educação de Crianças de 0 a 6 anos (GT 7); Alfabetização, Leitura e Escrita (GT 10) e Educação de Pessoas Jovens e Adultas (GT 18) - da ANPED, no período supramencionado, totalizando 923 trabalhos avaliados. Desse montante, 17 foram selecionados, tendo como critério de seleção os títulos ou resumos dos artigos que apontavam referência à concepção do MST. Realizamos, ainda, uma pesquisa documental, tendo como fonte materiais presentes no sítio ${ }^{6}$ do Movimento e a proposta pedagógica editada no Dossiê MST Escola: Documentos e Estudos 1990 a $2001^{7}$. Propomos, inicialmente, delinear a concepção de educação popular que assumimos como perspectiva do presente trabalho, a qual é a base para análise da concepção de educação lançada pelo Movimento. No segundo momento, identificamos a concepção de educação do MST, buscando a relação dessa concepção com a educação popular. Por fim, analisamos como a dimensão educacional do MST tem se apresentado no âmbito dos artigos publicados pela ANPED.

\section{Definição de educação popular}

Escrever sobre educação popular, nos dias de hoje, remete-nos à importância de refletir o

5. O Setor de Educação do MST originou-se, como destaca Lerrer (2012), no início dos anos 1980, em plena Ditadura Militar, no acampamento Encruzilhada Natalino da Fazenda Annoni, no Rio Grande do Sul, no qual uma equipe de professores começou a ensinar as crianças. O Setor foi composto por professores, pais, alunos e lideranças, assumindo o compromisso de articular as questões práticas para o funcionamento da escola e cuidar para que toda criança tivesse acesso a ela.

6. Disponível em: <http://www.mst.org.br>. Acesso entre outubro e dezembro de 2011.

7. Cf. Caderno de Educação no 13 (Edição Especial): Dossiê MST Escola: Documentos e Estudos $1990-2001$. Apresenta materiais produzidos pelo MST sobre educação ao longo da trajetória histórica do movimento. 
propósito de uma educação não tradicional, criada pelo povo e para o povo, em que todo aprendizado gesta-se de maneira diferente, voltado para a realidade dos seus autores. Nesta, de acordo com Freire (1981), educar é um ato de partilha de experiências, crenças e desejos de uma realidade melhor. Para o autor, a educação realiza-se por meio de processos contínuos e permanentes de formação, que possuem a intencionalidade de transformar a realidade a partir do protagonismo dos sujeitos. Esse processo educacional acontece de forma dialógica, ao ensinar e aprender, sendo fundamental a interação entre educador e educando.

Um dos exemplos de educação popular é a Pedagogia dos Movimentos de Luta Pela Terra, a qual é fundamentada nas elaborações de Paulo Freire e visa implantar uma educação voltada para a realidade do povo, suas vivências e experiências de vida, utilizando todo o aprendizado com vistas a alcançar o viver em uma sociedade mais justa para todos. Sendo assim, um dos principais objetivos da educação popular é transformar a realidade excludente que marcou e marca historicamente a vida do povo. Segundo Freire (1981), esse processo só será realizado a partir do momento em que o povo se reconhecer como sujeito de sua própria existência, percebendo a educação como ato de conhecimentoedetransformaçãosocialepolítica.

Acrescenta-se, ainda segundo Freire (2005), que a classe dominante encontra diferentes estratégias para não perder a dominaçãosobreooprimido. Porisso, elatambém domina formas e termos do opressor. É neste contexto que devemos indagar o que realmente compreendemos como educação popular e, tomando tal questão como referência, indagar também sobre o significado de cultura popular.

Certamente que tais problematizações podem nos levar a diferentes abordagens e posturas. Corroboramos com Chauí (2006), que, se apoiando em Gramsci (2006), sustenta a opção de entender a cultura popular na compreensão da diferença de classe, concebida pela autora como um fator de exclusão social. Nessa trajetória, Chauí aponta:

Se o nacional é o passado resgatado pela consciência e pelo sentimento popular, o que é o popular para Gramsci? Do ponto de vista político as análises gramscianas tomam o popular segundo as determinações econômicas e sociais da divisão social das classes [...]. Porém, do ponto de vista da cultura, o popular recebe alguns sentidos novos e mesmo surpreendente. [...] $\mathrm{Na}$ perspectiva gramsciana, o popular na cultura significa, portanto, a transfiguração expressiva de realidades vividas, conhecidas, reconhecíveis, cuja interpretação pelo intelectual, pelo artista e pelo povo coincide. Essa transfiguração pode ser realizada tanto pelos intelectuais "que se identificam com o povo" como por aqueles que saem do próprio povo, na qualidade de seus intelectuais orgânicos. (CHAUÍ, 2006, p.17-20).

Dessa forma, o popular perpassa pelo reconhecimento do povo e das suas vivências, por sujeitos que compreendem essa realidade, mesmo sem ter efetivamente participado dela, ou por sujeitos que saíram dessa realidade. Assim, fazendo um contraponto com as ideias de Freire, pautados na concepção de divisão de classes, abordada por Marilena Chauí, percebemos que a referida autora as concebe como um fator de exclusão social.

Freire (2011) sempre lutou por uma sociedade justa, questionando o poder da classe dominante, que geralmente legitima seus valores e ideais, concebendo os saberes e conhecimentos populares como subalternos e justificando ainda mais a divisão de classes. Neste contexto, Chauí (2006), pautada na concepção de Gramsci, também nos auxilia na compreensão das imposições da classe dominante, apresentando-nos a seguinte análise:

Gramsci afirma que existe uma religião 
e uma moral do povo, muito diversas daquelas organizadas pelos intelectuais da hierarquia eclesiástica e da classe dominante; a religiosidade e a moralidade do povo instituem crenças e imperativos de conduta muito mais fortes, tenazes e eficientes do que os da religião e da moral oficiais. (CHAUÍ, 2006, p. 20).

Portanto, para Gramsci (2006), o povo possui uma maneira própria de perceber cultura, valores e tradições - de acordo com o que lhe é legítimo - que se diferencia dos valores impostos pela classe dominante.

Para Freire (1996), o saber popular configura-se como matéria prima para o ensino que, por meio da conscientização da classe dominada, cria a possibilidade de superar as situações de opressão, ou seja, uma educação conscientizadora pautada no saber popular. Sendo assim, a concepção de educação popular em que nos baseamos está pautada nos conceitos de Freire, expostos anteriormente, e na concepção da diferença de classes como fator de exclusão dos sujeitos das classes populares. Neste contexto, a educação popular configurase como um movimento de resistência e de busca de superação da situação de dominação imposta pelas diferenças de classes. A cultura, os valores, as tradições, as vivências e o conhecimento do povo ajudam a compor a educação popular e são instrumentos que auxiliam na superação de situações de exclusão dos sujeitos.

\section{Concepção de educação do MST}

O princípio central do movimento é buscar condições de vida que favoreçam a permanência do homem no campo e o redimensionamento da estrutura fundiária do Brasil. Atualmente, o MST segue a mesma filosofia e a implementação de políticas adotadas no I Congresso Nacional, em 1985, porém, acrescentam-se as políticas reafirmadas no V Congresso Nacional do MST, em 2007. Assim, há diferentes compromissos firmados pelo Movimento, dentre eles, destacamos a preocupação em relação à educação dos assentados. Tal preocupação levou o MST a investir parte de suas ações na busca de um sistema próprio de educação. Nesse caminho, é escopo central do Movimento desenvolver a consciência crítica dos educandos, possibilitando o acesso aos conteúdos que levem à reflexão e à aquisição de uma visão de mundo ampliada e diferenciada do discurso oficial; a construção e a transmissão da história e do significado da luta pela conquista da terra e da reforma agrária; além de desenvolver atividades que visem à capacidade técnica dos alunos para experiência de trabalho produtivo, conforme afirma Morissawa (2001).

O direito à educação básica e a construção de escolas públicas com metodologias e práticas educativas adequadas à realidade dos assentamentos e acampamentos são metas do Setor de Educação do MST. Com o propósito de atender tais intentos, o Setor se fundamenta em princípios filosóficos e pedagógicos, os quais se complementam ${ }^{8}$. Os princípios filosóficos tratam da visão de mundo, das concepções gerais em relação à pessoa, à sociedade e à educação e são os fundamentos dos objetivos estratégicos do trabalho educativo do MST. O primeiro princípio filosófico é a educação para a transformação social, em que o processo pedagógico está entrelaçado às questões políticas, pois visa à construção de uma nova ordem social, baseada na justiça, na democracia e em valore humanistas e socialistas.

A educação para o trabalho e a cooperação representa o segundo princípio filosófico. Este é fundamental, pois as práticas educacionais que acontecem nos acampamentos e assentamentos não podem desconsiderar a

8. Caderno de Educação no 8 (Princípios da Educação do MST), publicado em julho de 1996, faz parte do Dossiê MST Escola. Tomamos tal material como referência para a discussão dos princípios filosóficos e pedagógicos do Movimento. 
luta pela reforma agrária e os desafios que se colocam para o provimento de novas relações de produção no campo e na cidade. Assim, todas as questões do assentamento devem ser resolvidas conjuntamente pela comunidade, tais como comercialização, acesso às novas tecnologias, moradia, conquista de escolas, postos de saúde, área de lazer e outros. No entanto, o segundo princípio filosófico é prejudicado pela herança do individualismo e do conservadorismo, presentes nos próprios membros. Por isso, justificam a necessidade de uma formação voltada para a cooperação e a incorporação criativa das lições da história da organização coletiva do trabalho. Além disso, o MST defende uma educação voltada para a omnilateralidade, trabalhando, em cada uma de suas práticas, as várias dimensões da pessoa de modo associativo, tendo por base a realidade social em que a ação humana acontece.

O Movimento tem como pressuposto educacional também a difusão de valores humanistas e socialistas. Para tanto, asseguram que é fundamental uma formação que provoque rupturas com os valores dominantes da sociedade atual, centrada no lucro e no individualismo, cultivando com os educandos e educandas o sentimento de indignação diante de injustiças, que ocasionam a perda da dignidade humana. Incentivam também o companheirismo e a solidariedade como referência nas relações entre as pessoas e a busca da igualdade combinada com o respeito às diferenças.

Na concepção do Movimento, a educação é um processo permanente de formação e transformação humana. Acredita-se na capacidade de transformação do ser humano, na qual as pessoas educam e são educadas num processo constante, dinâmico e ininterrupto.

Sustentados nesses princípios filosóficos, o Setor de Educação do Movimento estabeleceu os princípios pedagógicos da proposta de educação do MST. Tais princípios referem-se ao jeito de realizar as ações educacionais, para que se concretize a filosofia do Movimento e esclareçam os paradigmas presentes tanto nas escolas do campo quanto nas escolas dos centros urbanos.

$\mathrm{O}$ primeiro princípio diz respeito à relação entre prática e teoria. A prática social dos seus educandos constitui a base do processo formativo. Para tanto, é necessário um currículo organizado de forma a exigir respostas práticas e ações metodológicas capazes de articular as situações da realidade aos saberes propedêuticos, conforme avaliação de Caldart (1996, p. 159):

Consideramos superada historicamente aquela visão de que a escola é apenas um lugar de conhecimento teórico que depois, fora dela, é que serão aplicados na prática. [...] Queremos que a prática social dos/ das estudantes seja a base do seu processo formativo, seja matéria prima.

A combinação metodológica entre ensino e capacitação representa outro princípio, que se sustenta na diferenciação entre ensino e capacitação. O ensino teria como principal característica o momento do conhecimento (teoria), que vem antes da ação. Na capacitação, ao contrário, a ação antecede o conhecimento sobre ela. Na lógica da capacitação, cabe ao educador colocar o educando em relação com a atividade objetivada, provocar necessidades de aprendizagem, conforme Caldart (1996). Cada passo dado em direção à consolidação desse princípio pedagógico reflete-se na ideia de educaçãoomnilateral, ouseja, nabasefilosóficado Movimento. Portanto, o propósito é combinar o:

[...] ensino com a vivência concreta dos/das estudantes na sua experiência de organizar a escola em forma de cooperativa, para que este objetivo concreto Ihes capacite em cooperação, mas também em novos comportamentos, novas atitudes pessoais em relação ao coletivo. (CALDART, 1996, p. 167).

A realidade como base da produção do conhecimento é o terceiro princípio. 
Segundo Silva (2002), uma determinada situação específica do grupo torna-se um tema gerador ${ }^{9}$ em que a realidade irá gerar subsídios para que se aprofundem os estudos teóricos sobre determinado assunto, bem como deverá criar condições para que um pequeno problema chegue às causas mais abrangentes da situação. Dessa visão macro, que partiu de um problema específico, tem-se a consolidação do tema gerador, ou seja, a realidade, que serviu de referência para a aprendizagem e ocasionou a apreensão do sujeito, possibilitou o desenvolvimento de uma metodologia que visa a indissociabilidade da prática e teoria.

O quarto princípio versa sobre conteúdos formativos socialmente úteis. Seguem a concepção de que os conteúdos são instrumentos para atingir os objetivos do grupo, tanto ligados ao ensino quanto à capacitação. Isso não significa que qualquer conteúdo serve, ao contrário, eles devem ser escolhidos adequadamente de acordo com os princípios filosóficos, segundo Caldart (1996). Para Silva (2002), essa definição usada pelo Movimento traz implícitos os interesses sociais e as posições políticas do grupo, ou seja, selecionar aqueles conteúdos que, de um lado, estejam na perspectiva de distribuição igualitária dos conhecimentos produzidos pela humanidade e, de outro lado, que tenham a potencialidade pedagógica necessária para educar os cidadãos para a transformação social.

O quinto princípio destaca a educação para o trabalho e pelo trabalho. Tal princípio tem como pressuposto que a função da escolaéformar seus educandos para as exigências complexas dos processos produtivos. Assim, a educação deve voltar-se tanto para a realidade quanto para prática, atendendo as questões que norteiam o trabalho. À medida que o trabalho passa a fazer parte do mundo pedagógico, o sentido da educação transcende a sala de aula e contribui para a superação da dicotomia teoria e prática.

O sexto princípio anuncia o vínculo entre processos educativos e processos políticos, seguindo a mesma vertente de Freire (1981). Esse princípio tem como pressuposto que a educação não é alheia à sociedade e, por isso, há uma relação fundamental com a política. Estabelecer vínculo orgânico entre processos educativos e processos políticos significa questionar as relações de poder, organização e gestão. A importância do vínculo orgânico entre processo educativo e cultura é afirmada em um dos documentos base do Movimento:

O que não podemos perder de vista é o objetivo maior de tudo isso, e que diz respeito não a um simples resgatar da chamada cultura popular, mas principalmente ao produzir uma nova cultura; uma cultura da mudança, que tem o passado como referência, o presente como vivência que ao mesmo tempo em que pode ser plena em si mesma, é também antecipação do futuro, nosso projeto utópico, nosso horizonte. (MST, 1996, p. 20).

A gestão democrática ou participativa é outro princípioque permeiatodosos demaisenão está restrito apenas à esfera escolar, mas também à gestão dos assentamentos e acampamentos, tornando-se um referencial importante nas inter-relações estabelecidas na coletividade.

$\mathrm{Na}$ perspectiva do MST, os princípios supracitados deverão agir diretamente na prática e na estruturação da escola, conforme sugere Silva (2002, p. 53):

O professor quando trabalha sozinho, se frustra por não conseguir atingir esses princípios;

9. Esse termo foi originalmente criado por Paulo Freire. Para o autor, "investigar o tema gerador é investigar o pensar dos homens referindo à realidade, é investigar seu atuar sobre a realidade, que é a práxis. Os temas, na verdade, existem nos homens, em suas relações com o mundo, referidos a fatos concretos. Um mesmo fato objetivo pode provocar em uma subunidade epocal, um conjunto de temas geradores, e, noutra, não os mesmos necessariamente. Há, pois, uma relação entre o fato objetivo, a percepção que dele tenham os homens e os temas geradores". (FREIRE, 1987, p. 98-99). 
desta forma, no ato da troca, da reflexão e cooperação que começa a existir uma nova prática e, consequentemente, uma nova sociedade. Os coletivos pedagógicos devem ser entendidos como equipes ou núcleos de educação, grupos de estudo e discussão, fóruns, congressos e todos os momentos que se tornam espaços privilegiados para a auto formação permanente.

É ainda importante ressaltar que a fundamentação teórica e a pesquisa são elementos essenciais para a consolidação da Proposta do Movimento, as quais são garantidas pela formação do professor. Detendo-nos, ainda, aos apontamentos de Silva (2002), podemos apresentar outro recorte sobre o processo de ensino-aprendizagem sugerido pelo movimento:

\begin{abstract}
Assim como no princípio que trata do ensino e da capacitação, a formação do professor deve ser norteada pelas suas vivências e pelo embasamento e produção teórica, ou seja, é a prática que reflete na teoria e que gera novas práticas a serem reavaliadas em um ciclo infinito que visa sempre o seu aperfeiçoamento. A aprendizagem ocorre da combinação entre processos pedagógicos coletivos e individuais. O MST em diversos momentos aborda a necessidade dos processos coletivos. (SILVA, 2002, p. 54).
\end{abstract}

Apesar dos princípios serem os mesmos para todos os níveis de ensino, poderá haver práticas diferenciadas, de acordo com o nível de escolaridade, mas os princípios filosóficos e pedagógicos devem ser referências tanto para escola quanto para a comunidade. As metodologias de ensino, de acordo com Freire (1994), necessitam propiciar o acesso aos conhecimentos já acumulados pela humanidade e garantir o direito à educação, despertando nos educandos, o amor pela terra e a consciência de que precisam lutar pela conquista de seus direitos e, assim, reestruturar o espaço de vivência escolar. Na proposta educacional do MST, baseada em Paulo Freire, o homem tem ontológica vocação de ser mais, sua natureza é a vocação de humanizar-se. Somente em comunicação tem sentido a vida humana, por isso, na relação educando e educador, o pensar do educador só ganha autenticidade no pensar do educando, mediatizados ambos pela realidade, que, no caso do movimento dos trabalhadores rurais, envolve o pensar de sua própria condição de homem do campo e as relações sociais que os envolvem. É nesse contexto que a concepção de educação do MST assume perspectivas de uma educação popular.

\section{A presença do MST na ANPED: aproximações dos trabalhos publicados com a concepção de educação e de escola do Movimento}

Na busca pela compreensão de qual concepção de educação tem sido desenvolvida nos trabalhos publicados na ANPED acerca do MST e de que modo essas publicações se distanciam/aproximam dos princípios filosóficos e pedagógicos explicitados pelo Movimento, selecionamos 17 artigos que destacam, no título, referências à temática mencionada. O período analisado correspondeu aos anos de 2000 (23a reunião) a 2010 (33a reunião), assumindo como critério o ano inicial em que os textos integrais dos trabalhos e pôsteres estavam disponíveis no sítio da ANPED, em formato pdf.

Tendo como referências os artigos analisados, destacamos a quantidade de trabalhos produzidos em cada ano, de acordo com cada GT e, em especial, a quantidade (entre parênteses) dos trabalhos que fazem referência ao MST em seus títulos e resumos (Tabela 1). 
Tabela 1 - Trabalhos produzidos pela ANPED referentes ao MST, 2000-2010.

\begin{tabular}{|c|c|c|c|c|c|c|c|c|c|c|c|}
\hline \multirow[b]{2}{*}{ Grupos de Trabalho (GT) } & \multicolumn{11}{|c|}{ Quantidade de trabalhos e pôsteres por ano } \\
\hline & § & ঠ & $\stackrel{\overbrace{}}{\bigodot}$ & $\stackrel{m}{\stackrel{\wp}{8}}$ & $\stackrel{ナ}{ঠ}$ & $\stackrel{\stackrel{n}{̊}}{\stackrel{2}{N}}$ & 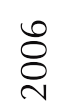 & $\stackrel{\curvearrowright}{\bigodot}$ & $\stackrel{\infty}{\bigodot}$ & 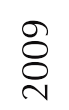 & $\stackrel{\circ}{\stackrel{0}{0}}$ \\
\hline $\begin{array}{l}\text { GT 3: Movimentos Sociais e } \\
\text { Educação }\end{array}$ & 09 & $\begin{array}{l}12 \\
(1)\end{array}$ & $\begin{array}{l}12 \\
(1)\end{array}$ & $\begin{array}{l}11 \\
(1)\end{array}$ & $\begin{array}{l}18 \\
(1)\end{array}$ & $\begin{array}{l}27 \\
(1)\end{array}$ & 12 & 10 & 15 & 9 & 15 \\
\hline GT 6: Educação Popular & $\begin{array}{l}16 \\
(1)\end{array}$ & 14 & $\begin{array}{l}14 \\
(1)\end{array}$ & 17 & 15 & $\begin{array}{l}30 \\
(2)\end{array}$ & $\begin{array}{l}18 \\
(1)\end{array}$ & $\begin{array}{l}25 \\
(1)\end{array}$ & $\begin{array}{l}15 \\
(1)\end{array}$ & 17 & 11 \\
\hline $\begin{array}{l}\text { GT 7: Educação de crianças } \\
\text { de } 0 \text { a } 6 \text { anos }\end{array}$ & 20 & 20 & 16 & 9 & 15 & $\begin{array}{l}28 \\
(1)\end{array}$ & 26 & 23 & 21 & 21 & 17 \\
\hline $\begin{array}{l}\text { GT 10: Alfabetização, } \\
\text { leitura e letramento }\end{array}$ & 15 & 15 & 15 & 12 & 15 & 23 & 12 & 17 & 19 & 20 & 18 \\
\hline $\begin{array}{l}\text { GT 18: Educação de Pessoas } \\
\text { Jovens e Adultas }\end{array}$ & 21 & $\begin{array}{l}16 \\
(1)\end{array}$ & 14 & 10 & $\begin{array}{l}13 \\
(1)\end{array}$ & $\begin{array}{l}26 \\
(1)\end{array}$ & 16 & 15 & 20 & $\begin{array}{l}19 \\
(1)\end{array}$ & 16 \\
\hline $\begin{array}{l}\text { Total de trabalhos } \\
\text { publicados }\end{array}$ & 81 & 77 & 71 & 59 & 76 & 134 & 82 & 90 & 90 & 86 & 77 \\
\hline $\begin{array}{l}\text { Total de trabalhos } \\
\text { publicados que fazem } \\
\text { referência ao MST no título. }\end{array}$ & 1 & 2 & 2 & 1 & 2 & 5 & 1 & 1 & 1 & 1 & 0 \\
\hline
\end{tabular}

Fonte: Os autores.

Conforme a Tabela 1, há um total de 923 trabalhos publicados ao longo de dez anos, nos cinco GT analisados, sendo que: em 2000, 2003, 2006 a 2009, dos trabalhos apresentados, apenas 1 mencionava o MST em seus títulos; nos anos 2001, 2002 e 2004 foram identificados 2 trabalhos sobre o MST; em 2005, obtivemos o maior número de publicações, totalizando 134 trabalhos, dos quais 5 faziam referência e, em 2010, dos 77 trabalhos, nenhuma referência. Em uma análise inicial, de acordo com a tabela, observamos ainda um número limitado de publicações que se dedicam ao debate do MST, especialmente quando consideramos que a ANPED apresenta GT específicos para a temática Educação Popular e Movimentos Sociais.

\section{O teor das publicações da ANPED acerca da concepção de educação do MST}

Compõem o grupo de trabalhos dos autores selecionados, na ordem cronológica de suas publicações: Furtado e Brandão (2000), Beltrame (2001), Silva (2001), Azevedo (2002), Casagrande (2002), Souza (2003), Paiva (2004), Silva (2004), Foerste (2005), Falkembach (2005), Lenzi (2005), Arenhart (2005), Batista (2005, 2006; 2007), Nascimento e Neves (2008) e Silva (2009a). Iniciamos com Furtado e Brandão (2000), que apresentam o acompanhamento do trabalho desenvolvido pelo Instituto Nacional de Colonização e Reforma Agrária (INCRA) e o 
MST. Ao enfatizar suas análises acerca do MST, as autoras destacam como o Movimento se apoia na discussão sobre a necessidade de superação da dimensão e demanda da educação no campo. Afirmam ainda que o Movimento está imbricado na luta pela conquista da escola nos assentamentos, como uma educação pública para os povos do campo a partir da ação de sujeitos locais e da participação popular.

Beltrame (2001) analisa, em seu trabalho, como professores e professoras, que atuam nas escolas do MST, vivenciam suas práticas pedagógicas ancorados nos princípios do Movimento. As experiências pedagógicas dos/ das docentes estão pautadas na prática política, em processos coletivos de melhoria da vida no campo, na valorização da cultura camponesa, seus saberes e riquezas. Segundo a autora, professores e professoras reconhecem fazer parte de um projeto educacional e político mais amplo, que busca a valorização da população camponesa e a transformação social. Beltrame (2001) segue elucidando que a proposta do MST é investir no processo de formação de sujeitos dentro da escola pública, na valorização do professor, reconhecendo-o como um articulador das diversas formas da vida associativa local, os quais participam de todas as atividades do MST e são as "lideranças", demonstrando adesão aos princípios e valores do grupo. $\mathrm{Na}$ escola, esses profissionais têm uma prática pedagógica alimentada nessa atividade política.

Silva (2001) aponta como o foco central de seu trabalho, a investigação da densidade das expectativas, interesses e desejos dos/as trabalhadores/as em aprender. Segundo a autora, o MST incentiva a discussão e a promoção de ações práticas voltadas para a adoção de valores humanistas e socialistas, dentre os quais destaca a solidariedade e a cooperação. Sendo assim, busca, na sua pesquisa, compreender o que impulsiona os trabalhadores e trabalhadoras rurais a voltar a estudar, concluindo aspectos como: facilidade na superação de obstáculos tanto na vida pessoal como social, desenvolvimento de habilidades, maior inserção e desempenho no mundo do trabalho. Assim, de acordo com o primeiro princípio filosófico do Movimento, a autora ressalta que as práticas educacionais valorizam o companheirismo, o afeto entre as pessoas, a comunhão, a partilha e o amor à classe trabalhadora, à justiça social, à dignidade e à vida humana.

Azevedo (2002), ao traçar os caminhos e descaminhos de um processo de educação no meio rural, situando uma experiência do PRONERA (Programa Nacional de Educação na ReformaAgrária) no Rio Grande do Norte, destaca que um dos polos de contestação à ausência de uma política de educação própria do homem do campo tem sido trilhado pelo MST. O autor centra sua análise na expressão política que o Movimento sustenta acerca da educação a partir do reconhecimento das especificidades do viver rural (tempo-espaço-cultura e de sua produção identitária). Outro ponto afirmado é a recusa em ver a educação no meio rural reduzida ao ensino de formas de aumento da produtividade pela introdução de novas técnicas agrícolas.

Por sua vez, Casagrande (2002) discute a inserção do MST na perspectiva da educação como práxis social, mediada pela produção e socialização do conhecimento. A autora explicita que apesar do Movimento desenvolver uma pedagogia articuladora com a consciência política, com a luta de classes e com a organização revolucionária, evidencia que a materialização de tal educação transformadora necessita de um trabalho de conscientização radical sobre a proposta da educação apontada, por meio da capacitação e da formação continuada; a luta por salários dignos para os educadores dos assentamentos; condições adequadas para o desenvolvimento da prática pedagógica; o acesso às novas tecnologias; a inserção em organizações políticas coletivas que possam refletir a realidade imposta e a implantação do Projeto Político Pedagógico e do Projeto 
Histórico desse Movimento, rompendo com a visão dualista entre sujeito e objeto e retomando a dialética enquanto possibilidade do pensar.

Souza (2003) busca, por meio de seu texto, refletir sobre a luta pela educação formal nos assentamentos, os processos de educação não formal que acontecem nos movimentos sociais e a articulação entre esses movimentos e a sociedade civil na elaboração de projetos para assentamentos. Nesse contexto, a autora destaca que essa luta busca, além da garantia da escola pública, práticas pedagógicas diferenciadas que considerem a realidade de luta dos alunos e alunas. Ressalta, ainda, no que tange à educação nos assentamentos, a busca pela articulação entre educação e trabalho, objetivando facilitar a organização das atividades produtivas nos assentamentos.

Paiva (2004) analisa as práticas educativas, enfocando suas possibilidades e limitações no fazer militante do movimento social. Conforme a autora, os documentos produzidos e as ações realizadas no campo da formação revelam que o MST tem investido na formação/educação, com o objetivo de capacitar e qualificar os militantes e dirigentes para intervir nas diversas esferas da vida social. O texto menciona algumas práticas populares como o trabalho de base, os cursos destinados aos treinamentos das lideranças, no caso os militantes e a necessidade da escolarização. Paiva observa que os documentos e as práticas contestatórias empreendidas pelo MST estão ancorados na matriz discursiva da política emancipatória, com tendência a supervalorizar sua potencialidade política e minimizar a política da vida. Silva (2004) por meio de um estudo realizado com educadores da EJA (Educação de Jovens e Adultos) do MST, no Planalto Central Catarinense, procura compreender as diversas formas de comunicação e linguagem que permeiam essa modalidade de educação no Movimento. O autor considera que essas linguagens são diferenciadas das urbanas, estando impregnadas de ideologias e significados próprios do Movimento, e representadas com mais frequência por gestos e oralidade do que a linguagem escrita. Por isso, o autor destaca a importância do domínio da linguagem escrita para o Movimento, como instrumento de resistência, visto que, para o autor, a leitura e a escrita assumem um papel de formação política de seus militantes.

Ainda atrelado aos princípios filosóficos, Silva (2004) destaca o estudo das múltiplas linguagens dos assentados por meio da Mística dos Sem Terra, visto que essas atividades levam em consideração todas as aspirações, sonhos e utopias dos militantes, como também representa a vida e o cotidiano dos assentados e acampados na luta pela Reforma Agrária. Silva (2004) também aponta para o desenvolvimento de práticas que partem da mística e dos temas geradores, de acordo com Freire (2011). Foerste (2005) indica os resultados da análise do curso de formação de professores dos assentamentos e demonstra como tais iniciativas contribuem para a valorização social da profissão docente, no desenvolvimento profissional e na garantia de qualidade de uma educação voltada para a realidade do campo. Enfatiza a necessidade do MST, do PRONERA, do Grupo Permanente de Trabalho de Educação do Campo/MEC e das Universidades de fundamentar discussões para a implementação de políticas públicas que consolidem programas de educação do campo e da constituição de estratégias para o desenvolvimento territorial sustentável. No que se refere à identificação da concepção de educação do MST, presente no trabalho do autor, ressalta a luta coletiva, a educação pautada na relação com os outros e no trabalho da terra, como a busca de dignidade.

Falkembach (2005) discorre sobre a trajetória formativa de um grupo de integrantes do MST, detendo-se da singularidade do vir a ser desses sujeitos nas suas individualidades e como parte do movimento social. Pontua que 
o processo educativo de tais sujeitos - em suas individualidades - está atrelado ao princípio ontológico do potencial educativo do coletivo, tendo na terra um forte elemento de identificação do Movimento, pois ela representa trabalho, produção, moradia, vida, morte e reencontro na luta. Ainda, a autora identifica em seu trabalho, o reconhecimento dos princípios educacionais do MST apregoados nos discursos dos sujeitos entrevistados, como: direção coletiva, divisão de tarefas, respeito às aptidões, disciplina, estudo, formação de quadros, luta de massas e vinculação permanente entre direção do Movimento e base. Outro aspecto importante do trabalho é a constatação de uma concepção de educação política e de resistência (ocupar, resistir e produzir), que exige a permanente movimentação (formação e ação) dos sujeitos.

Lenzi (2005) identifica e analisa em seu trabalho como as significações da prática docente e política, expressas em textos imagéticos, são apreendidas por assentados/as vinculados/as ao MST; de que modo contribuem para constituí-los/as como educadores/as da EJA e como os retratam como educadores/ as, por meio de fotografias. O artigo busca contextualizar seu tempo e espaço, com o objetivo de adentrar na especificidade da ação educativa desses sujeitos educadores.

No GT-7, Educação de Crianças de 0 a 6 anos, identificamos que, no período analisado, Arenhart (2005) faz a proposição de análise da infância no MST. Dentre os princípios destacados pela autora, destacamos a mística, a relação conteúdo escolar e realidade vivida, a transformação social, a relação educação-trabalho-comunidade, a humanização, o uso dos temas geradores, a organização coletiva e a consciência de classe.

Batista (2005) que, ao falar sobre a educação popular vivenciada nos movimentos e nas lutas empreendidas pelos setores das classes populares, destaca as experiências de educação popular em ONGs, associações comunitárias, centros de cultura popular, práticas de economia solidária em associações, cooperativas, feiras e as propostas e programas de Educação dos Movimentos sociais, especialmente do MST. Nesses programas, vivenciam-se relações sociais de solidariedade, de ajuda mútua, de cooperação, tendo como preocupação maior a formação de seres humanos em todas as suas dimensões, caracterizando-se, assim, uma educação omnilateral.

Na esteira dessa discussão, Batista (2006) destaca que a educação concebida pelo MST deve assumir um compromisso coletivo com uma visão de campo, como um lugar de vida, cultura, produção, moradia, educação e lazer. Discutindo a educação ambiental, a autora sustenta a necessidade do respeito, a especificidade social, étnica e cultural dos seus sujeitos. Destaca, ainda, que o MST tem como ponto central, a compreensão da educação como um processo amplo que ocorre nas práticas cotidianas do Movimento. Em outro artigo publicado por Batista (2007), ainda que não especifique pontualmente o MST, a autora discute a concepção de educação do campo, relacionando-a com as propostas dos movimentos sociais, dentre os quais o MST, destacando as características que envolvem a pedagogia do Movimento, centrada na discussão teórica de Caldart (2000).

A partir das vozes dos sujeitos constituintes de um assentamento do MST acerca de suas experiências educacionais vividas, suas projeções na busca do saber escolar, e, ainda, pela relação e a compreensão que possuem sobre estes saberes que buscam na escola para o seu projeto de vida, o artigo de Nascimento e Neves (2008) procuram identificar o processo de construção dessas representações. Com isso, discutem as relações de saber impostas no ambiente escolar, uma vez que a consciência da incompletude é que direciona o sujeito do campo para a busca do saber para interagir com o mundo e com sujeitos iguais e diferentes deles. 
Assim, as autoras explicitam, por meio de seus trabalhos, as contradições e os conflitos existentes na nossa sociedade, entre os mundos científico, cotidiano e o das políticas públicas. Nessa nova dinâmica da vivência e saberes desses sujeitos, a necessidade de aprender novas formas de ações e de perceber os outros saberes direcionam as perspectivas e os desejos dos assentados para além daqueles que historicamente permitem-se ver na escola. Ele é um saber prático, pois precisa responder a uma necessidade vivida e social.

Silva (2009) busca, por meio da pesquisa desenvolvida com estudantes de Assentamentos Rurais do programa "Educação, Campo e Consciência Cidadã", analisar as relações entre as trajetórias escolares e as representações acerca do referido projeto. Nesse sentido, a autora destaca que a trajetória escolar dos alunos e alunas foi marcada pelo trabalho e por processos de exclusão e violência que levaram quase todos à evasão escolar. Destaca também o papel da educação como instrumento de emancipação dos sujeitos, possibilitando uma melhora nos relacionamentos familiares, sociais e até mesmo na compreensão da importância da luta pela terra.

\section{Aproximações e distanciamentos entre os artigos analisados}

Percebemos ao compreender o teor de cada artigo, no que concerne à concepção de educação, o processo dialético desenvolvido na relação intrínseca entre a concepção de mundo, de homem e de educação em tais publicações. Dentre as nossas análises um fato relevante é que dos 17 trabalhos, 14 foram desenvolvidos por mulheres, ora individualmente, ora em dupla e somente três foram produzidos por homens. Contudo, ao longo do trabalho, essencialmente, as autoras se referem ao gênero masculino. Esses dados demonstram que as mulheres são atuantes como docentes e pesquisadoras, mas que há uma tendência em retratar o processo de reflexão educacional como um campo próprio ao gênero masculino, ainda que uma das novidades dos últimos quarenta anos tenha sido

[...] o avanço da produção científica e acadêmica feminista no mundo e a emergência de novos fundamentos teóricos para interpretar a histórica discriminação das mulheres. (MELO; SABBATO, 2007, p. 3).

Furtado e Brandão (2000), Beltrame (2001), Silva (2001), Casagrande (2002), Azevedo (2002), Paiva (2004), Silva (2004), Foerste (2005), Lenzi (2005), Falkembach (2005), Arenhart (2005), Batista (2005), Nascimento (2008) e Silva (2009a) sinalizam, como elemento fundamental do Movimento, a educação vinculada ao primeiro princípio filosófico do Movimento, que trata da transformação social. Por esse motivo, a educação é apresentada como uma forte bandeira de luta do MST, sendo, portanto, considerada uma expressão política. Dentro do Movimento, a educação é concebida como elemento intrínseco da própria realidade social, superando a visão da escola como uma instituição isolada que tanto marca a educação tradicional. É relevante, entretanto, pontuar que, Casagrande (2002), ao mencionar o princípio da educação envolvida com a transformação social, destaca a necessidade de o Movimento materializar tal princípio, visto que, segundo a autora, nem sempre esse princípio se efetiva na realidade do MST.

Outro elemento recorrente é o destaque do Movimento preocupado com a constituição de novos princípios dos educandos pautados no humanismo e socialismo. Assim, nos artigos é acentuada a valorização do coletivo, da partilha, da justiça social, ou seja, o compromisso de todos com todos e com a causa do Movimento, conforme Furtado e Brandão (2000), Silva (2001), Souza (2003), Foerste (2005), Falkembach (2005), Arenhart (2005), Batista (2005) e Silva (2009a).

Esses princípios analisados são acrescidos da discussão sobre a necessidade de uma 
educação própria do homem do campo, o que nãosignifica, conformeFurtadoeBrandão(2000), Azevedo (2002), Foerste (2005), Falkembach (2005), Arenhart (2005), Batista (2006; 2007) e Nascimento (2008) reduzir a educação ao ensino de formas para aumentar a produtividade pela introdução de novas técnicas agrícolas.

O terceiro princípio pedagógico do MST toma a realidade como base da produção do conhecimento. Nesse sentido, Silva (2004), Lenzi (2005), Falkembach (2005), Arenhart (2005), Batista (2006) e Nascimento (2008) mencionam a necessidade de tal princípio, que aparece, porém, de forma superficial nos artigos analisados. Destacamos apenas Silva (2004), Falkembach (2005) e Arenhart (2005) que fazem referências mais pontuais ao tema, quando valorizam a mística dos militantes na dimensão pedagógica.

Dentre os valores formativos demandados da educação dos militantes, Foerste (2005) e Batista (2006) ressaltam o compromisso com o meio ambiente. No que se refere à utilização dos temas geradores no processo educativo, destacam-se os autores Lenzi (2005) e Silva (2009a), ainda que a notória quantidade de artigos tome como referência as concepções de Freire $^{10}$ acerca da educação. Falkembach (2005) destaca-se por adentrar a vários princípios do MST, presentes também nos outros artigos analisados, porém, acrescenta ainda, reflexões acerca da necessidade da vinculação permanente no Movimento entre as lideranças e bases do MST. Outro aspecto relevante é o apontamento da formação permanente, tendo como foco a ação educativa de ocupar, resistir e produzir.

Concluímos que o sentido primeiro da educação no Movimento sinaliza para a centralidade da educação transformadora, emancipadora, problematizadora, dialógica, que leve à formação de sujeitos comprometidos com um novo mundo transformado. Apontamos, para estudos posteriores, a necessidade de pesquisas que aprofundem suas análises sobre os conceitos de educação formal e não formal, visto que são poucos que diferenciam se a prática educativa requisitada no Movimento demanda por uma educação vinculada ou não ao sistema educativo e como seria o enfrentamento de mobilizar uma educação transformadora inserida num contexto marcado pela dominação de classes. Dentre os trabalhos, apenas o de Souza (2003) aponta claramente a necessidade de uma escola pública vinculada à educação formal nos assentamentos.

Destarte, consideramos predominantes as aproximações e as referências desenvolvidas nas respectivas publicações, no que compete às concepções de educação e de escola oriundos do Movimento. Tais publicações reafirmaram a presença, os processos e os resultados de trabalhos que envolvem os princípios filosóficos e pedagógicos dos sujeitos inseridos no MST, como homens em relação consigo mesmo, com o outro, com a comunidade e com o mundo. Esse emaranhado de relações fortalece o processo identitário coletivo por meio dos princípios de educação do Movimento.

Todas as publicações apontaram para conceitos-chavedasrelaçõesestabelecidas, como a dialogicidade, a participação ativa dos alunos/ as, a construção coletiva, a gestão compartilhada, o processo de formação ético, política e a reflexão-ação crítica para a transformação social. Desse modo, como afirma Freire:

10. Para maiores análises acerca da presença de Paulo Freire e suas concepções incorporadas pelo Movimento, indicamos a leitura do artigo "A contribuição de Paulo Freire para a educação popular: uma análise do GT de Educação Popular da ANPED", de Ruth Pavan (2011). 


\section{Referências}

ARENHART, D. A educação da infância no MST: o olhar das crianças sobre uma pedagogia em movimento. In: Reunião Anual da ANPED, 28., 2005, Caxambu. Anais... Caxambu: ANPED, 2005. Disponível em: <http://28reuniao.anped.org.br/>. Acesso em: 11 nov. 2013.

AZEVEDO, A. A. Traçando caminhos e descaminhos de um processo de educação no meio rural: reflexões a partir de uma experiência do PRONERA no Rio Grande do Norte. In: Reunião Anual da ANPED, 25., 2002, Caxambu. Anais... Caxambu: ANPED, 2002. Disponível em: <http://25reuniao. anped.org.br/>. Acesso em: 11 nov. 2013.

BATISTA, M. S. X. Os movimentos sociais cultivando uma educação popular do campo.In: Reunião Anual da ANPED, 29., 2006, Caxambu. Anais... Caxambu: ANPED, 2006. Disponível em: <http://29reuniao.anped.org.br/>. Acesso em: 15 nov. 2013.

. Educação popular em movimentos sociais: construção coletiva de concepções e práticas educativas emancipatórias. Reunião Anual da ANPED, 28., 2005, Caxambu. Anais... Caxambu: ANPED, 2005. Disponível em: <http://28reuniao.anped.org.br/>. Acesso em: 11 nov. 2013.

A educação popular do campo e a realidade camponesa. Reunião Anual da ANPED, 30., 2007, Caxambu. Anais... Caxambu: ANPED, 2007. Disponível em: < http://30reuniao.anped.org. br/>. Acesso em: 12 nov. 2013.

BRANDÃO, M. L. P.; FURTADO, E. D. O que se sabe e o que se faz sobre a educação no contexto dos assentamentos rurais- colocando gás na lamparina... Reunião Anual da ANPED, 23., 2000, Caxambu. Anais... Caxambu: ANPED, 2000. Disponível em: <http://23reuniao.anped.org.br/>. Acesso em: 13 nov. 2013.

BELTRAME, S. A. B.. MST, professoras e professores: sujeitos em movimento. Reunião Anual da ANPED, 24., 2001, Caxambu. Anais... Caxambu: ANPED, 2001. Disponível em: <http://24reuniao. anped.org.br/>. Acesso em: 14 nov. 2013.

CALDART, R. S. Princípios da educação no MST. Caderno de Educação, n. 13, São Paulo, 2006. Disponível em: <http://www.mst.org.br/node/2454>. Acesso em: 20 nov. 2013.

. Pedagogia do movimento sem terra. São Paulo: Expressão Popular, 2000.

CASAGRANDE, N. O processo de trabalho pedagógico no MST: contradições e superações no campo da cultura corporal. Reunião Anual da ANPED, 25., 2002, Caxambu. Anais... Caxambu: ANPED, 2002. Disponível em: <http://25reuniao.anped.org.br/>. Acesso em: 15 nov. 2013.

CHAUÍ, M. Cidadania cultural: o direito à cultura. São Paulo: Fundação Perseu Abramo, 2006.

FALKEMBACH, E. M. F. MST, um discurso-ação que convoca um vir-a-ser. Reunião Anual da ANPED, 28., 2005, Caxambu. Anais... Caxambu: ANPED, 2005. Disponível em: < http://28reuniao.anped. org.br/>. Acesso em: 16 nov. 2013.

FOERSTE, E. Pedagogia da terra: diálogos entre MST e universidade. Reunião Anual da ANPED, 28., 
2005, Caxambu. Anais... Caxambu: ANPED, 2005. Disponível em: < http://28reuniao.anped.org. br/>. Acesso em: 16 nov. 2013.

FREIRE, P. A concepção "bancária" da educação como instrumento da opressão. Seus pressupostos, sua crítica. In: . Pedagogia do oprimido. 47. ed. Rio de Janeiro: Paz e Terra, 2005.

Cartas a Cristina: reflexão sobre minha vida e minha práxis. 2. ed. São Paulo: Editora da UNESP, 2003.

Educação e Mudança. Rio de Janeiro: Paz e Terra. 1981

1996.

Pedagogia da autonomia: saberes necessários à prática educativa. São Paulo: Paz e Terra,

Pedagogia do oprimido. Rio de Janeiro: Paz e Terra. 2011.

GRAMSCI, A. Cadernos do cárcere. Os intelectuais. O princípio educativo. Jornalismo. Tradução de Carlo Nelson Coutinho. Rio de Janeiro: Civilização Brasileira, 2006.

LENZI, L. H. C. Significações da prática docente retratadas por educadores de jovens e adultos do MST. Reunião Anual da ANPED, 28., 2005, Caxambu. Anais... Caxambu: ANPED, 2005. Disponível em: <http://28reuniao.anped.org.br/>. Acesso em: 16 nov. 2013.

LERRER, D. F. Preparar gente: a educação superior dentro do MST. Estudos Sociedade e Agricultura, Rio de Janeiro, v. 20, n. 2, p. 451-484, 2012.

MELO, H. P.; SABBATO, A. D. Gênero e trabalho rural. 2007. Disponível em: < http://www.iica.int/ Esp/regiones/sur/brasil/Lists/DocumentosTecnicosAbertos/Attachments/464/Alberto_Di_Sabbato_-_ Hildete_P_de_Melo_-_NEAD_-G\%C3\%AAnero_e_Trab_Rural.pdf >. Acesso em: 10 set. 2013.

MORISSAWA, M. A história de luta pela terra e o MST. São Paulo: Expressão Popular, 2001.

MOVIMENTO DOS TRABALHADORES RURAIS SEM TERRA. Alfabetização de jovens e adultos: como organizar. Caderno de Educação, São Paulo, n. 8, p. 3-32, jan. 1999.

. Educação do MST. Disponível em: <http://www.mst.org.br/histórico/educação1htmle2 html.2001>. Acesso em: 11 nov. 2013.

NASCIMENTO, I. P.; NEVES, J. D. V. As representações sociais que as mulheres e homens assentados possuem sobre os saberes que buscam na escola para os seus projetos de vida. Reunião Anual da ANPED, 31, 2008, Caxambu. Anais... Caxambu: ANPED, 2008. Disponível em: < http://31 reuniao. anped.org.br/>. Acesso em: 16 nov. 2013.

PAIVA, I. A. A dimensão educativa do fazer militante no MST. Reunião Anual da ANPED, 27., 2004, Caxambu. Anais... Caxambu: ANPED, 2004. Disponível em: < http://27reuniao.anped.org.br/>. Acesso em: 16 nov. 2013.

PAVAN, R. A contribuição de Paulo Freire para a educação popular: uma análise do GT de Educação Popular da ANPED. Periódico do Programa de Pós-Graduação em Educação da UCDB, Campo Grande, n. 31, p. 245-260, jan.-jun. 2011. 
SILVA, A. P. A educação como estratégia de luta. 2002. 101f. Monografia (Graduação em Pedagogia) - Universidade Presbiteriana Mackenzie, São Paulo. 2002.

SILVA, L. H. Projeto educação, campo e consciência cidadã: representações sociais e trajetórias de educandos do PRONERA. Reunião Anual da ANPED, 32., 2009, Caxambu. Anais... Caxambu: ANPED, 2009. Disponível em: < http://32reuniao.anped.org.br/>. Acesso em: 16 nov. 2013.

SILVA, R. C. C. As Aprendizagens escolares como objeto do desejo dos trabalhadores e trabalhadoras rurais sem-terra. Reunião Anual da ANPED, 24., 2001, Caxambu. Anais... Caxambu: ANPED, 2001. Disponível em: <http://24reuniao.anped.org.br/>. Acesso em: 16 nov. 2013.

SILVA, S. R. Movimento, comunicação e linguagem na educação de jovens e adultos do MST. Reunião Anual da ANPED, 25., 2004, Caxambu. Anais... Caxambu: ANPED, 2004. Disponível em: <http://25reuniao.anped.org.br/>. Acesso em: 20 nov. 2013.

SILVA, M. V.; FONSECA, A. M. Educação em movimento: políticas e práticas educativas do movimento de trabalhadores rurais sem terra. Ensino em Re-Vista, Uberlândia, v. 16, n. 1, p. 201230, jan./dez. 2009.

SOUZA, M. A. Educação em assentamentos: relações (re) criadas no cotidiano do movimento social. Reunião Anual da ANPED, 26., 2003, Caxambu. Anais... Caxambu: ANPED, 2003. Disponível em: <http://26reuniao.anped.org.br/>. Acesso em: 16 nov. 2013.

Submetido em 21 de fevereiro de 2014.

Aprovado em 10 de março de 2014. 